\title{
Strategies to improve the fertility of frozen-thawed boar semen for artificial insemination
}

\author{
J. Roca' ', H. Rodríguez-Martínez ',2, J.M. Vázquez' ${ }^{1}$ A. Bolarín', M. Hernández', \\ F. Saravia ${ }^{2}$, M. Wallgren ${ }^{2}$ and E.A. Martínez ${ }^{1}$ \\ 'Department of Medicine and Animal Surgery, Faculty of Veterinary Medicine, Campus de Espinardo, \\ University of Murcia, E-30071, Murcia, Spain; '2Division of Comparative Reproduction, Obstetrics \\ and Udder Health, Faculty of Veterinary Medicine and Animal Science, Swedish University of \\ Agricultural Sciences (SLU), Uppsala, Sweden; Correspondence to: Dr. Jordi Roca, Department of \\ Medicine and Animal Surgery, Faculty of Veterinary Medicine, Campus de Espinardo, University of \\ Murcia, E-30071 Murcia, Spain
}

Although cryopreservation of boar semen for artificial insemination (AI) was developed 35 years ago, cryopreservation conditions and $\mathrm{Al}$ strategies are still considered sub-optimal. Al with excessive numbers of frozenthawed sperm (5-6 $\times 10^{9}$ cells), still does not achieve fertility levels similar to Al using liquid semen because of reduced sperm survival. Frozenthawed (FT) spermatozoa have therefore not been the preferred option for commercial breeding programmes. However, substantial progress has been made regarding boar sperm cryopreservation. Adjustment of cooling and re-warming rates to biophysical properties of boar spermatozoa, new sperm package systems and the achievement of accurately consistent freezing of large numbers of samples using programmable freezers have contributed to post-thaw survival rates above $50 \%$, a threshold similar to that used for bull Al-semen. Moreover, these post-thaw sperm survival rates are consistent within a large population of boars selected for sperm freezability potential, as occurs with Al-bull sires. When such post-thaw boar semen is deposited intra-utero, acceptable fertility (in terms of farrowing rates and litter size) is obtained. Currently, the most effective application of FT-semen for Al is achieved using deep uterine-AI (DUI) which allows placement of a minimal semen dose (in volume 0.5 to $10 \mathrm{~mL}$ and sperm number 0.5 to $1 \times 10^{9}$ total spermatozoa) into the anterior $1 / 3$ of one uterine horn, with levels of fertility close to $\mathrm{Al}$ with liquid semen. However, owing to their shorter life span, FT-boar spermatozoa require an Al-to-ovulation interval not longer than 4-6 h, making peri-ovulatory $\mathrm{Al}$ a pre-requisite to obtain the highest possible fertility. Spontaneous ovulation most often occurs when two-thirds of oestrus has passed. Estimation of the duration of oestrus, taking into account the weaning-to-oestrus interval, is helpful when establishing appropriate Al-schedules. However, as the length of oestrus varies within and between farms, different $\mathrm{Al}$ strategies should be established a priori. The 
development of bio-sensors for spontaneous ovulation will widen the use of $\mathrm{Al}$ with frozen-thawed frozen semen.

\section{Introduction}

Artificial insemination (AI) is the most world-widely applied breeding tool in pig farms (Weitze, 2000). It is well established that Al with fresh or cooled boar semen is a simple, successfut and economical procedure, able to achieve high farrowing rates $(>80 \%$ ) and litter sizes ( $>10$ piglets born per litter) comparable to those obtained after natural mating. However, to maximise the advantages of $\mathrm{Al}$, it is important to include cryopreserved spermatozoa, as this is the only practical alternative for global transport of sperm and long-lasting preservation of genetic material. Such strategies could restore male populations lost by removal of infected sires or the creation, or improvement, of nucleus breeding herds. Freezing-thawing (FT) of boar semen for cervical Al, a technique initiated 35 years ago, can be conducted to cover these expectations, but it is not practical and inexpensive enough for full application in commercial breeding.

Following the birth of piglets conceived by cervical Al using FT-spermatozoa at the beginning of the 1970's (Crabo and Einarsson, 1971; Graham et al., 1971; Pursel and Johnson, 1971), several trials were conducted during the same decade, some of them achieving high fertility levels (reviewed by Johnson, 1985). In spite of these promising results accomplished under controlled experimental conditions, there was a little use of FT-semen in commercial farms. The variability in freezing success between boars, the high sperm numbers required per dose and the low fertility levels achieved compared to those obtained with liquid semen, were among the major limiting factors (Johnson, 1985; Reed, 1985). From a statistical viewpoint, less than $1 \%$ of total Als were, at that time, performed worldwide with FT-semen (Reed, 1985). During the following years, a wealth of new information about different aspects of frozen storage of boar semen has accumulated, and many attempts have been made to enhance fertility with Al using FT-semen (for more details, see reviews of Bwanga, 1991; Woelders, 1997; Johnson et al., 2000). Despite these efforts, at the beginning of the new millennium the percentage of sows inseminated with FT-semen was, surprisingly, still less than $1 \%$ (Wagner and Thibier, 2000) and the limiting factors remained those listed above (Johnson et al., 2000). This apparent lack of progress could relate to the continuous use of empirical approaches when cryopreserving boar spermatozoa (see review of Watson, 1995) as well as the absence of research-oriented technological development aiming to improve the transport of FT-spermatozoa through the genital tract of sows (see review of Martínez et al., 2001).

At present, there is an extensive requirement for establishing sperm cryobanks for both export and conservation of superior genetic lines, and for reserving supplies in response to disease-related disasters. In response, our laboratory has created four cryobanks, with more that 20,000 Al doses, during the past 3 years. In addition, FT boar semen is a prerequisite for the best use of some of emergent reproductive biotechnologies (for details see Sommer et al., 2002; Gerrits et al., 2005).

The present review centres on the improvement of sperm cryosurvival using standardised methods for freezing and the development of efficient Al strategies; these are important pre-requisites to achieve fertility levels that would increase the use of FT-boar spermatozoa in commercial pig breeding.

\section{Improvement of sperm cryosurvival}

Increasing the survival of spermatozoa subjected to freezing and thawing will require optimisation of methods for cryopreservation as well as minimising existing intra- and inter-animal variation 
in sperm freezability present in a boar population unselected for this purpose. The obvious objective is to retrieve maximal numbers of spermatozoa with preserved potential fertilising capacity post-thaw after using a single freezing method.

\section{Optimisation of sperm cryopreservation methodology}

Poor sperm survival after thawing has traditionally represented the major limitation to the successful application of cryopreserved boar semen in commercial Al programmes, since it largely explained the low fertility results achieved. Thus, the primary objective of any strategy to enhance the fertility after Al with FT-spermatozoa must be to improve cryopreservation and maximise sperm cryosurvival. During the past few years, specific cryobiological studies focussing on the adaptation of cooling and rewarming rates to biophysical properties of boar spermatozoa, changes of sperm package systems as well as the accurate and consistent freezing of large numbers of samples led to the optimisation of cryopreservation protocols (see review of Holt, 2000a).

Cooling and re-warming rates are the most critical variables influencing sperm cryosurvival and thus a pre-requisite for an optimal sperm cryopreservation protocol. Furthermore, spermatozoa from different species respond differently to cooling and re-warming, requiring specific knowledge. Determination of the rates of water permeability using differential scanning calorimetry has confirmed, for instance, that the optimal cooling rate for freezing boar spermatozoa is $30^{\circ} \mathrm{C} / \mathrm{min}$ when a standard concentration of glycerol is used (Devireddy et al., 2004). Unfortunately, similar non-empirical studies are yet lacking considering re-warming and its effects on sperm cryosurvival. The general consideration is that the response of spermatozoa to rewarming depends on the cooling rate used. With a cooling rate of $30^{\circ} \mathrm{C} / \mathrm{min}$, a rapid rewarming of $1,200^{\circ} \mathrm{C} / \mathrm{min}$ - seems most suitable (Fiser et al., 1993).

New packaging systems have also improved sperm survival post-thaw. Historically, boar spermatozoa were routinely packaged in maxi $(5-6 \mathrm{~mL})$ plastic tubes or straws containing the most appropriate number of sperm as one Al-dose $\left(5-6 \times 10^{9}\right.$ cells). However, the use of macrotubes or maxi-straws involves certain cryobiological problems as the cooling and thawing rates may differ across the straw. Weitze et al. (1987) found that extended boar spermatozoa packaged in maxi-straws froze 3.75 times faster at the periphery than in the centre, resulting in a significant lower post-thaw sperm survival compared to sperm packaged in medium-straws $(0.5$ $\mathrm{mL}$ ). Later, optimal freezing and thawing were obtained by packing boar spermatozoa into French medium-straws (Fiser and Fairfull, 1990) and now most boar semen is packed for freezing into $0.5 \mathrm{~mL}$ straws. These are not only better from a cryobiological viewpoint, they are also more practical, given the relative high number of spermatozoa $\left(2 \times 10^{9} \mathrm{cells} / \mathrm{mL}\right)$ that can be packaged per straw (Saravia et al., 2005), the good post-thaw sperm survival (Carvajal et al., 2004) and the acceptable in vivo fertility levels achieved (Bussiere et al., 2000). An alternative package system containing either $5 \times 10^{9}$ cells in $5 \mathrm{~mL}$ (FlatPack') has also been developed. The promising results of post-thaw sperm survival (Eriksson and Rodriguez-Martínez, 2000), in vitro penetrability (Eriksson et al., 2001) and in vivo fertility (Eriksson et al., 2002), together with their possibilities to package a large number of spermatozoa, indicate, from a practical and commercial viewpoint, that FlatPack is a very suitable method for packaging commercial single doses of frozen boar spermatozoa for cervical Al. Recently, a modification of the procedure (holding $1.4 \times 10^{9}$ cells in $0.7 \mathrm{~mL}$, MiniflatPack) has been devised and tested for deep uterine-Al (DUI; Saravia et al., 2005; Wongtawan et al., 2005).

From a practical viewpoint, the replacement of the traditional freezing in a static gradient of nitrogen-cooled air ( $\mathrm{LN}_{2}$ vapours) by controlled-rate freezers (also using $\mathrm{N}_{2}$-cooled air but whose rate of cooling is controlled by a computer) has been an important advance for commercial 
production of frozen Al-doses. Although the overall effectiveness of some programmable freezing devices can be questionable (for more details see Holt, 2000b; Thurston et al., 2003), those with a precise temperature control system capable of measuring both internal and external temperatures of straws can most effectively control the rate of cooling (Medrano et al., 2002; Kumar et al., 2003). Thus, effective controlled-rate freezers optimise freezing, providing accurate cooling rates for a large batch of samples and minimising sample-to-sample variability. Together, these developments allow production of frozen doses with an improved and consistent post-thaw sperm survival.

\section{Selection of Al boars for good freezability}

Optimal sperm cryosurvival depends not only on cryopreservation methodologies, but also on the individual variation each boar shows regarding susceptibility of the ejaculated spermatozoa to sustain cryoinjury. An essential difference between liquid and FT-semen is the different response of the ejaculated spermatozoa when cooled. While spermatozoa of practically all boars respond similarly well to liquid storage, where the cooling is marginal, the response varies greatly when more intense cooling is used. So, irrespective of breed or genetic line, important boar differences on sperm freezability have been well established (Thurston et al., 2001). When these researchers objectively classified boars as "good", "moderate" or "bad" freezers according to their post-thaw sperm quality, a large percentage $(32.6 \%, 42$ boars from of 129 tested) were identified as bad freezers.

In a recent experience in our laboratory, during the creation of a sperm cryobank for commercial purposes, a total of 255 ejaculates from 85 boars ( 3 ejaculates per boar) were frozen. To establish their post-thaw sperm quality, 2 straws of each ejaculate were thawed to undergo computer-assisted assessment of motility (CASA) and microscopic evaluation of plasma membrane and acrosome integrity after staining with a triple fluorescent staining $(\mathrm{R} 123+\mathrm{PI}+\mathrm{FIT}$ PNA). Following the same criteria as Thurston et al. (2002), the ejaculates and boars were classified as "good", "moderate" or "bad", with $44.3 \%$ being found as "good" and $27.8 \%$ as "bad" ejaculates, respectively (for details see Fig. 1). These data clearly demonstrated important differences in sperm freezability among ejaculates, corroborating earlier results (Thurston et al., 2002). However, the most relevant finding of our study was that whereas all ejaculates from 29 boars were classified as "good", all ejaculates from 18 boars were classified as "bad" (Fig. 1a), showing that the spermatozoa from some boars had consistent difficulties to overcome the freezing and thawing cycle.

From a commercial viewpoint, eliminating these "bad" freezers as providers of ejaculates for cryopreservation and $\mathrm{Al}$ is the most practical way to improve the fertility levels of FTspermatozoa. Any boar selected as a sire in an Al programme using FT-semen should, in addition to his genetic merits, also be selected according to the freezability potential of his semen. However, there is currently no single predictive test to determine the freezability potential of an ejaculate, because post-thaw sperm survival has been traditionally based on unpredictable pre-freeze values (Roca et al., 2000). The identification of different molecular markers linked to genes controlling sperm freezability in a genomic analysis of 22 Large White boars, indicated the individual variability in freezability among boars has a genetic basis (Thurston et al., 2002). This important finding is the first step to develop a simple and feasible molecular or genetic test capable of marker-identification of "good" or "bad" freezer boars from a blood sample. Unfortunately, such a test is not yet commercially available.

An alternative strategy, effective to identify "bad" freezers, could be to implement a suitable freezability test. Based on our experience, cryopreserving 5-10 mL of the sperm-rich fraction of an ejaculate and assessing the post-thaw sperm quality (evaluation of objective 
A

B
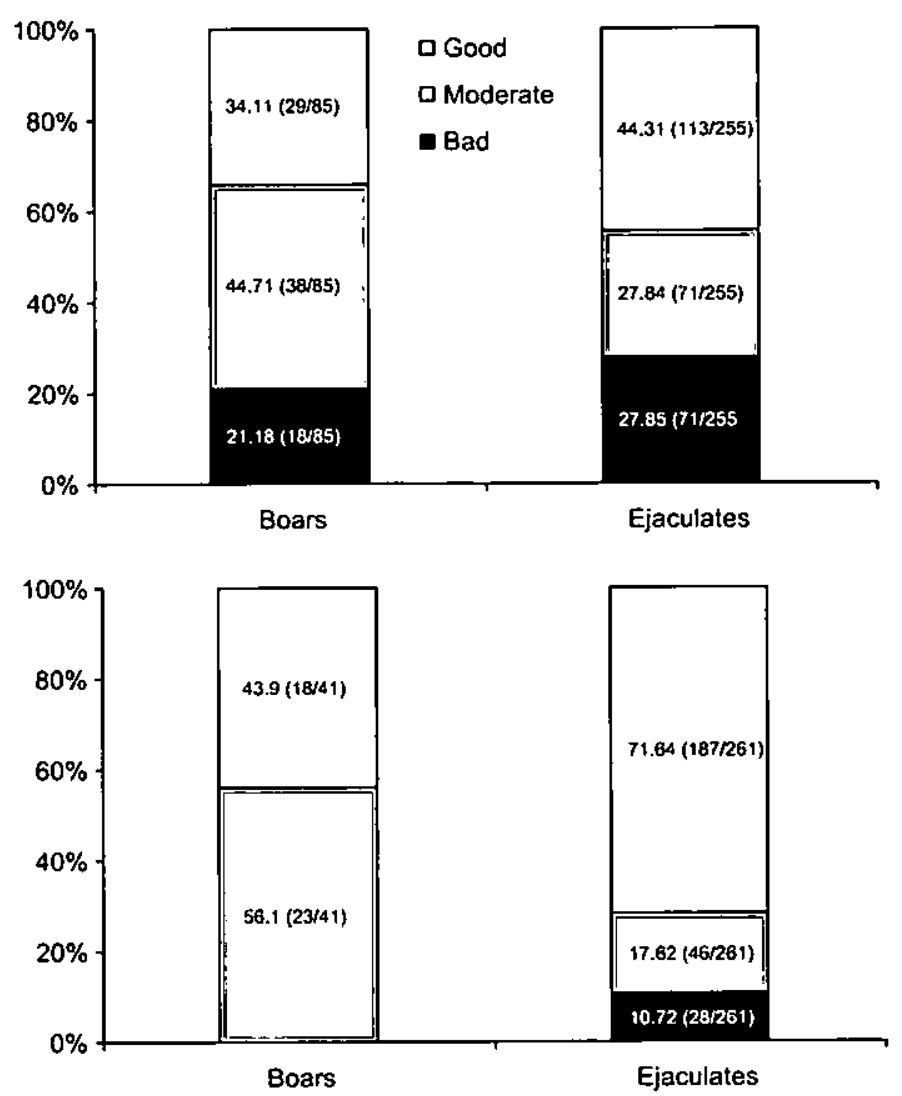

Fig. 1 Distribution of boar and ejaculates of two different sperm cryobanks founded with frozen ejaculates collected from unselected (a) or selected (b) boars according to sperm freezability. Boar and ejaculates were classified according their post-thaw sperm quality (motility and viability) assessed from two thawed Beltsville Thawing Solution (BTS)-resuspended straws per ejaculate held $30 \mathrm{~min}$ in a water bath at $37^{\circ} \mathrm{C}$. The ejaculate classification criteria were: "good" ( $\geq 50 \%$ of spermatozoa are motile and viable after thawing), moderate $(36-49 \%)$ or "bad" $(\geq 35 \%)$. Boar classification criteria were: "good" (all ejaculates had good post-thaw sperm quality), "moderate" (ejaculates with different post-thaw sperm quality) or "bad" (all ejaculates had bad post-thaw sperm quality). Viable sperm were those that after incubation with three fluorescent probes (deoxyribonucleic acid specific fluorochrome propidium iodide, the mitochondria specific fluorochrome rhodamine-123 and the acrosome specific fluorochrome fluorescein isothiocyanate-labeled peanut agglutinin), showed green stain only on the midpiece under fluorescent microscopy (Roca et al., unpublished).

motility and viability of two thawed straws using the above procedures) could be enough to identify "bad" freezers. So, before the creation of a second sperm cryobank, we checked the freezability potential of all boar candidates using such a test. Out of 51 boar candidates, 10 $(19.6 \%)$ were classified as "bad" freezers and therefore eliminated as ejaculate providers. Finally, the cryobank was founded with 261 ejaculates from 41 selected boars (5 ejaculates minimum per boar). According to post-thaw sperm quality, 28 ejaculates $(10.7 \%)$ were classified as "bad". Regarding boars, whereas in 18 boars $(43.9 \%)$ all their ejaculates were classified as "good", in the remaining 23 boars only isolated ejaculates were classified as "bad" (Fig. 1b). 
These data showed clearly that a simple freezability test may be suitable for both minimising ejaculate variability among boars and enhancing the overall post-thaw sperm quality of frozen ejaculates.

Differences in sperm cryosurvival rates can also be found within the same boar (i.e. among ejaculates). This intra-boar variability could be attributed to boar health status, reproductive management, frequency of ejaculation or differences in ejaculate processing before or during the cryopreservation process. Thus good boar management and careful processing of the ejaculate would help to minimise intra-boar ejaculate variability on post-thaw sperm survival.

\section{More efficient insemination strategies}

The lower fertility of FT-semen compared to liquid semen is traditionally related to the low proportion of functional spermatozoa that survive cryopreservation. However, with the recent improvements mentioned above, survival levels of thawed, cryopreserved boar spermatozoa are now quite satisfactory. Together with the possibility to select "good" freezers as semen providers, it is now possible to achieve reasonably high and consistent post-thaw sperm survival rates; over $50 \%$ of viable and motile spermatozoa in a large population of boar sires. It is noteworthy that such sperm survival rates are similar to those obtained in Al-bull sires, which have undergone selection pressure for freezability over decades in commercial dairy cattle breeding programmes (Vishwanath and Shannon, 2000). Therefore, the answer to the lower fertility might be more in relation to the site of sperm deposition in the female, as was the case in the bovine, where intrauterine Al contributed dramatically to the fertility rates achieved with FT-semen.

The profitable application of FT-semen on commercial pig Al programmes requires more efficient insemination strategies than at present, the final objective being to obtain high fertility levels using the lowest possible number of FT-spermatozoa. To maximise the efficiency of FT-semen, in terms of maximal fertility and prolificacy, critical factors such as proper placement of the semen in the sow 's genital tract and a proper timing of insemination ought to be considered.

\section{Insemination procedure: proper semen deposition}

The wealth of research performed with the aim of improving boar sperm cryopreservation protocols has, unfortunately, not been matched by the development of more efficient insemination techniques for FT-semen. The current insemination procedure includes the deposition of a large number of spermatozoa $\left(5-6 \times 10^{9}\right.$ cells) into the cervical canal, mimicking natural mating and using the same equipment as for liquid semen. Overall, the resulting fertility levels are usually low, indicating the poor efficiency of this insemination procedure, rather than the presumable lower quality of the semen. Therefore, from a practical viewpoint, other Al-procedures are to be tested to overcome the two major hurdles to the routine application of FTsemen in commercial farms, namely the high numbers of spermatozoa required per dose and the low fertility levels achieved.

The low efficiency of FT-semen after cervical deposition is not only a matter of concern for the pig; it has also been observed in other species where alternative insemination procedures are available, such as ovine. Direct intrauterine sperm deposition by laparoscopy is usual as an Al procedure in ewes, and fertility of FT-semen deposited in this way is higher than that obtained after cervical deposition (King et al., 2004). Moreover, fertility differences cannot be compensated by inseminating a larger number of thawed spermatozoa cervically. The low fertility obtained following cervical Al relates to the difficulty of the FT-spermatozoa to pass 
through the cervical barrier, progress into the uterus and reach the oviductal isthmus (see review by Salamon and Maxwell, 1995). A similar situation occurs in pigs, where in addition to the cervical folds, the extremely long uterine horns impair the ability of FT-spermatozoa to maintain their fertilising capacity when reaching the oviduct. Consequently, although as many as 5-6 $\times 10^{9}$ spermatozoa are cervically deposited, far fewer reach the oviductal reservoir. Certainly, the number of accessory spermatozoa in the zona pellucida of embryos can be as much as 10-fold lower in FT-spermatozoa compared to liquid preserved sperm, even when the Aldose contained twice as many sperm (Waberski et al., 1994; Wongtawan et al., 2005).

With the aim of reducing the number of spermatozoa per Al-dose without impairing fertility, two different techniques and devices have been developed for trans-cervical semen deposition into different regions of the uterus, namely into the uterine body (Post-Cervical-AI, PC-AI) or deep into one uterine horn (Deep Uterine Insemination, DUI). Both have achieved high fertility levels with liquid semen using $1 \times 10^{9}$ (PC-AI, Watson and Behan, 2002) or only $150 \times 10^{6}$ (DU1, Martínez et al., 2002) total spermatozoa per dose. In relation to their potential effectiveness using FT-semen, whereas at present no fertility data are available using the PC-Al procedure, promising results have been achieved using the DUI procedure.

The DUI technique involves the introduction of a flexible device through a conventional commercial Al spirette, previously inserted in the cervix folds as guide, into one uterine horn (for more details see Martínez et al., 2001). The DUl device is able to progress along the uterine lumen facilitating the deposition of the semen at, at least, the proximal $1 / 3$ of the horn, nearer to the utero-tubal junction, where the sperm reservoir is present in the pig (Martínez et al., 2002). A recent study monitored the effectiveness of using DUI to routinely inseminate FT-semen in commercial farms (Roca et al., 2003). Forty weaned sows were DUI twice at 30 and $42 \mathrm{~h}$ after onset of oestrus using low numbers of sperm $\left(1 \times 10^{9}\right.$ spermatozoa) suspended in a small volume $(7 \mathrm{ml})$ of fluid. The farrowing rate averaged $70 \%$ with a mean litter size of 9.25 piglets born. These fertility levels were comparable, or better, than some reported following conventional cervical Al with 5 fold more thawed spermatozoa (Hofmo and Grevle, 2000; Eriksson et al., 2002). Moreover, the fertility of FT-spermatozoa after DUI can be considered as "acceptable" compared to that obtained in the same farm after conventional $\mathrm{Al}$ using fresh semen $(84.2 \%$ farrowing rate and 9.88 piglets born per litter). Thus, it seems clear that the DUI procedure has the potential to achieve high fertility levels using a total number of FT-spermatozoa as low as $1 \times 10^{9}$. This means a 5 to 6 -fold decrease compared with current doses of FT-semen and a 2-to-3-fold decrease compared with current commercial doses of liquid semen. Thus, DUI could increase the effectiveness of FTspermatozoa by reducing the number of thawed spermatozoa required in each dose. Therefore, DUI with FT-semen is currently used by some pig genetic companies in Spain. Although DUI performance is currently satisfactory, research is in progress in order to standardise the DUI procedure for routine application of FT-semen under commercial conditions, including the determination of the minimal number of spermatozoa needed to obtain maximal fertility levels. As an example, farrowing rates close to $50 \%$ with 9 piglets born per litter have been reported, using as few as $250 \times 10^{6}$ frozen-thawed spermatozoa per dose (Bathgate et al., 2005). The use of contemporary small packs to freeze semen in conjunction with DUI makes the deposition of small volumes of thawed, non reextended semen deep intra-uterine possible. This approach avoids the deleterious effects of semen re-suspension post-thaw and of sperm losses associated with the reflux of semen after conventional $\mathrm{Al}$, while retaining normal sperm transport (Wongtawan et al., 2005). How sperm transport is elicited with these small volumes $(0.5$ to $7 \mathrm{~mL}$ of semen) deposited into one uterine horn appears more related to the inseminating device than to the insemination volume. The introduction of the long Al-catheter would trigger the spontaneous contractility of the female genital tract, thus contributing to the first phase of sperm transport (Rodriguez-Martinez et al., 2005). 
The above results clearly show that DUI is an efficient procedure for the routine application of FT-semen in commercial pig Al programmes, providing good fertility levels with low sperm numbers. However, concern has been raised about potential damage that the DUI device may cause to the endometrium, compromising the subsequent fertility of the sow. To investigate this, we compared the reproductive performance of conventional Als carried out with liquid semen before and after DUI-insemination on 159 weaned sows (A. Bolarín et al., unpublished). No differences were found $(P>0.05)$ in pregnancy rates $(87.4 \%$ versus $86.2 \%)$, farrowing rates $(84.9 \%$ versus $84.3 \%)$ or litter size $(11.08 \pm 0.17$ versus $11.50 \pm 0.15$ piglets born). Moreover, not-in-pig rates were also similar $(2.9 \%$ versus $2.2 \%, \mathrm{P}>0.05)$. In addition, among those sows that were not pregnant after DUI, showing a regular or irregular return to oestrus, there were no significant differences $(P>0.05)$ in pregnancy losses post breeding before or after DUI $(0.6 \%$ versus $2.5 \%$ ). Neither did more intensive experimental studies of the use of DUI record uterine damage when using the procedure (Wongtawan et al., 2005). Thus, it seems evident that the correct insertion of the DUI device into a uterine horn does not affect the subsequent fertility potential of the sows. Despite these reassuring data, it must be born in mind that DUI technology is still under development.

\section{Timing of insemination}

The fertility of FT-spermatozoa appears more influenced by the timing of Al relative to ovulation than by their post-thaw sperm quality. Thawed spermatozoa of all species studied have a limited life-span in the female genital tract, compared to fresh spermatozoa. Fertilisation of pig oocytes with FT spermatozoa has been successfully achieved only when inseminations were performed in a very short optimal period of 4-6 h before ovulation (Waberski et al., 1994). Sub-optimum Altimes before or after ovulation lead to low conception rates and/or litter sizes (see Johnson et al., 2000). Using DUI under experimental conditions, fertility of weaned sows inseminated with small doses of highly packed, frozen-thawed semen was related to the interval between DUI and spontaneous ovulation. The optimal interval was found to be between 8 and 4 hours before spontaneous ovulation (Wongtawan et al., 2005). The reduced life span of the FT-spermatozoa was evident with a significantly lower fertility and replenishment of the sperm reservoir if the interval Al-to-ovulation was longer. Under commercial conditions, the reduced functional life span of thawed spermatozoa in the sow genital tract was again clearly demonstrated in a recent field trial (Roca et al., 2002). Weaned, multiparous sows $(n=80)$ were DUl-inseminated at $30-32$ and $40-42 \mathrm{~h}$ after detection of oestrus, with $1 \times 10^{9}$ thawed spermatozoa resuspended to $7 \mathrm{~mL}$ of BTS. A few minutes before each DUI, the ovaries were examined by trans-rectal ultrasonography and sows were allotted into 3 different categories: $F$ sows: when follicles were visible during the two examinations, indicating pre-ovulatory DUI; $O$ sows: when ovulation was visible during one examination, indicating peri-ovulatory DUI; and C sows: when corpora haemorragica were visible during the two examinations, indicating post-ovulatory DUI. The farrowing rate was significantly $(p<0.01)$ higher in $O$ sows than in $F$ or $C$ sows (Table 1) and was similar $(P>0.05)$ to that achieved on the same farm using conventional $\mathrm{Al}$ with liquid semen $(70 / 85,82.3 \%)$. The data clearly demonstrate that good fertility can be achieved with FT-spermatozoa provided that Al is closely timed to ovulation.

As previously indicated, no comprehensive studies have been conducted to determine the number of FT-spermatozoa required per dose to achieve maximum fertility levels using the DUI procedure. It is clear that the number of spermatozoa per Al-dose influences fertility results (Flowers, 2001), especially when using FT-spermatozoa (Watson, 2000). In a recent field trial in which 228 weaned sows were DUI-inseminated with either $1 \times 10^{9}$ or $2 \times 10^{9}$ cells Bolarín et al. (2005), a 2 -fold increase in sperm number improved farrowing rate $(53.1 \%$ versus $70.0 \%$ respectively; $P<0.05)$. However, taking into account the ovarian status at the time of DUI, the improvement in farrowing rate was evident in F- $(52.8 \%$ versus $73.2 \%)$ and C-sows $(43.9 \%$ versus $60.6 \%)$, but not 
in O-sows $(81.1 \%$ versus $\mathbf{8 0 . 8} \%$ ). These results clearly demonstrated that the interval between DUI and ovulation is a more important determinant of fertility than the number of sperm per dose. However, it is important to remember that the sperm numbers used might still be in excess for the achievement of maximal fertility. Further studies are still needed to elucidate this.

Table 1. Farrowing rates and litter size of weaned sows according to their ovarian status at the time of deep uterine insemination (DUI). Sows were inseminated twice with $1 \times 10^{9}$ frozen-thawed spermatozoa at $30-32$ and 40-42 h after oestrous detection (adapted from Roca et al., 2002).

\begin{tabular}{lccc}
\hline Ovarian status at DUI & Sows $n(\%)$ & Farrowing $n$ (\%) & Litter size (mean \pm SEM) \\
\hline Pre-ovulatory (F-sows) & $13(16.3)$ & $5(38.5)^{\mathrm{b}}$ & $9.60 \pm 1.08$ \\
Peri-ovulatory (O-sows) & $59(73.7)$ & $48(81.4)^{\mathrm{a}}$ & $9.33 \pm 0.30$ \\
Post-ovulatory (C-sows) & $8(10)$ & $2(25)^{\mathrm{b}}$ & $7.00 \pm 1.00$ \\
TOTAL & 80 & $55(68.7)$ & $9.27 \pm 0.28$ \\
\hline
\end{tabular}

a,b Values with different superscript in the same column are significantly different $(P<0.05)$

Ultrasonography used as an ovulation diagnostic tool in herds is feasible, and although it is not a useful predictor for spontaneous ovulation (Soede et al., 1998), it is probably the best means available at present. In the absence of a better predictive tool, the possibilities to forecast the moment of ovulation are reduced to the assessment of the average duration of oestrus, which varies according to the interval from weaning to oestrus. Overall, spontaneous ovulation takes place when two-thirds of the standing oestrus period has elapsed (see review by Soede and Kemp, 1997). Using the recorded onset of oestrus-to-ovulation interval (checked by frequent transrectal ultrasonography, a time-consuming procedure) inseminations in weaned sows can thus be performed in the following oestrus at the expected ovulation time (Mburu et al., 1995; Wongtawan et al., 2005). Following this reasoning, we have achieved promising farrowing rates $(69.2 \%, 152 /$ $217)$ and litter sizes $(9.22 \pm 0.16$ piglets born per litter) in several trials in a large commercial farm (more that 3,000 breeding sows) with an insemination strategy that included two DUl-inseminations with a total of $1 \times 10^{9} \mathrm{FT}$-spermatozoa per dose carried out at $30-31$ and $36-37 \mathrm{~h}$ after onset of oestrus in sows weaned four days before. The short interval between DUls was established taking account of the short functional life span of FT-spermatozoa in the genital tract.

Unfortunately, the duration of oestrus is very variable and it is influenced by many factors including genetics and on-farm breeding management of sows (see review by Soede and Kemp, 1997). From a practical viewpoint, it is important to note that the duration of oestrus varies considerably between farms, which could explain the fertility differences recorded between farms when FT-semen from the same frozen batch was used (Eriksson et al., 2002). We evaluated this possibility recently (Bolarín et al., 2005). The same batch of FT-semen from a pool of ejaculates of several mature fertile boars was used to DUI-inseminate weaned sows in two different farms with similar reproductive management. A total of 179 sows (97 from farm $A$ and 82 from farm 8 ) were DUIinseminated at 30-31 and 36-37 h with $1 \times 10^{9}$ spermatozoa per dose. A few minutes before DUI, the ovaries were checked by trans-rectal ultrasonography and the sows allocated to category $F, O$ or $C$ as previously described. The overall farrowing rate differed $(P<0.01)$ between farms $(70.1 \%$ versus $51.2 \%$, farms $A$ and $B$, respectively). Distribution of sows according to ovarian status also differed $(\mathrm{P}<0.05)$ between farms $\left(17.5 \%, 72.2 \%\right.$ and $10.3 \%$ were classified as $F_{-}, \mathrm{O}$ - and $\mathrm{C}$-sows in farm A, versus $40.2 \%, 20.3 \%$ and $30.5 \%$ in farm B). Nevertheless, farrowing rates and litter size within the same ultrasonographic ovarian status did not vary between farms $(P>0.05)$. In either farm, similar high farrowing rates $(82.9 \%$ and $83.3 \%$ for $A$ and $B$ farm, respectively) and litter sizes $(9.38 \pm 0.26$ and $9.65 \pm 0.51$ for $A$ and $B$ farm, respectively) were achieved in $O$ sows. Consequently, these results suggest that fertility differences of FT-semen between farms were due, to a large extent, to different insemination-to-ovulation intervals. The low fertility levels in farm B 
were clearly due to a suboptimal Al-strategy. In conclusion, it is necessary to emphasise that before FT-semen is to be used for breeding, proper Al strategies must be established for each farm. A correct knowledge of the overall duration of oestrus, taking into account the weaning-to-oestrus interval (WOI), would be of great help in the establishment of the most appropriate Al strategy. Therefore, farmers should carry out a careful onset of oestrus detection and establish its duration taking into account the WOI.

In addition to farm differences, WOI affects the duration of oestrus (Mburu et al., 1995), which makes decisions on appropriate strategies to inseminate most of the sows within the short optimal period before ovulation more difficult. Moreover, seasonal influences are not to be disregarded. As an example, a recent experiment carried out in the southeast of Spain (Bolarin et al., unpublished observations) showed that the above reproductive parameters can vary largely depending on season on the same farm. The occurrence of ovulation was monitored, by use of trans-rectal ultrasonography, on 122 sows (58 and 68 during winter and summer, respectively). Data presented in Table 2, clearly indicate that some sows showed longer WOI and oestrous duration during summer, which implies a more heterogeneous ovulation time. These seasonal differences could be explained by the adverse effect of high environmental temperature (Peña et al., 1998). It is tempting to suggest that specific Al strategies should be designed for summer months in the warm regions to achieve consistent high fertility levels throughout the year when FT-semen is used. At present, to the best of our knowledge, no results are yet available. In particular, alternative $\mathrm{Al}$ schedules including a third insemination may be beneficial.

Table 2. Distribution of weaned sows according to weaning-to-oestrus and the onset of oestrus-to-ovulation intervals during winter (a) and summer (b) seasons within a single farm. Ovulation was checked by transrectal ultrasonography. (Bolarín et al., unpublished observations)

\begin{tabular}{|c|c|c|c|c|c|c|}
\hline \multirow{2}{*}{$\begin{array}{l}\text { (a) Onset of oestrus } \\
\text { to ovulation (h) }\end{array}$} & \multirow[b]{2}{*}{3} & \multicolumn{3}{|c|}{ Weaning to onset of oestrus (d) } & \multirow[b]{2}{*}{7} & \multirow[b]{2}{*}{ Mean $(\%)$} \\
\hline & & 4 & 5 & 6 & & \\
\hline 0 to $<12$ & & 1 & 1 & 1 & & $3(5.2)$ \\
\hline$\leq 12$ to $<24$ & & 5 & 8 & 2 & & $15(25.9)$ \\
\hline$\leq 24$ to $<36$ & 1 & 12 & 4 & 1 & & $18(31)$ \\
\hline$\leq 36$ to $<48$ & 4 & 11 & 2 & & & $17(29.3)$ \\
\hline$\leq 48$ to $<60$ & 1 & 2 & 1 & & & $4(6.9)$ \\
\hline$\leq 60$ to $<72$ & 1 & . & & & & $1(1.7)$ \\
\hline \multicolumn{7}{|l|}{$\leq 72$ to $<84$} \\
\hline \multirow{2}{*}{\multicolumn{7}{|c|}{$\begin{array}{l}\leq 84 \text { to }<96 \\
\geq 96\end{array}$}} \\
\hline & & & & & & \\
\hline \multirow[t]{2}{*}{ Total $(\%)$} & 7 & 31 & 16 & 4 & & 58 \\
\hline & $(12.1)$ & (53.4) & $(27.6)$ & (6.9) & & $(100)$ \\
\hline
\end{tabular}

\begin{tabular}{lcccccc}
\hline $\begin{array}{l}\text { (b) Onset of oestrus } \\
\text { to ovulation (h) }\end{array}$ & 3 & \multicolumn{7}{c}{ Weaning to onset of oestrus (d) } & 7 & Mean (\%) \\
\hline 0 to $<12$ & 4 & 5 & 6 & & $8(11.8)$ \\
$\leq 12$ to $<24$ & & 5 & 1 & 1 & 1 & $17(25)$ \\
$\leq 24$ to $<36$ & 1 & 9 & 2 & 3 & 2 & $16(23.5)$ \\
$\leq 36$ to $<48$ & 2 & 10 & 2 & 2 & & $15(22.1)$ \\
$\leq 48$ to $<60$ & 7 & 6 & 2 & & & $5(7.3)$ \\
$\leq 60$ to $<72$ & 3 & 3 & 2 & & & $5(7.3)$ \\
$\leq 72$ to $<84$ & & 1 & 2 & & & $1(1.5)$ \\
$\leq 84$ to $<96$ & 13 & 35 & 11 & 6 & 3 & 68 \\
$\geq 96$ & $(19.1)$ & $(51.5)$ & $(16.2)$ & $(8.8)$ & $(4.4)$ & $(100)$ \\
\hline Total $(\%)$ & & & & & & \\
\end{tabular}


Fixed insemination time

Unfortunately, inadequate or incorrect oestrous detection strategies are not unusual in farms, due to a lack of time and skilled labour. An alternative strategy is to use exogenous hormonal treatment (eCG followed by either hCG or GnRH analogues) to improve estimation of the time of ovulation in sows and thus improve the results of Al with FT-boar semen, particularly during the summer months or in those farms with inappropriate breeding management. A common protocol of synchronisation of ovulation time in weaned sows consists in the exogenous application of eCG $24 \mathrm{~h}$ after weaning, to promote ovarian follicular development, followed by hCG 60-72 h later, to induce ovulation. Overall, ovulation should occur $42-44 \mathrm{~h}$ after hCG application. The correct synchronisation of ovulation has an additional advantage since only a single $\mathrm{Al}$ at a fixed time is required, reducing expense in semen costs without fertility losses. Using the above synchronisation protocol, we have achieved high fertility levels $(77.5 \%$ of farrowing rate with $9.31 \pm 0.41$ piglets born per litter) in 49 weaned sows DUl-inseminated with $1 \times 10^{9} \mathrm{FT}$ spermatozoa per dose at $40 \mathrm{~h}$ after hCG application (Roca et al., 2003). Despite these promising results, fixed-time $\mathrm{Al}$ should be carefully evaluated and its implementation balanced against cost, benefits, animal welfare issues and eventual pharmaceutical residues.

\section{Concluding remarks}

The efficient inclusion of FT-boar semen on routine Al programmes in commercial farms is now feasible. This is possible because both current cryopreservation protocols and accurate selection of "good" freezers enable acceptable cryosurvival rates to be achieved. In addition, high fertility levels can be achieved with a reduced number of FT-spermatozoa following DUI. However, to obtain consistent high fertility levels, the semen must be inseminated close to ovulation. Fair estimation, but not accurate prediction, of spontaneous ovulation is only possible under very good management practice, making the development of prediction markers for ovulation a priority.

\section{Future directions}

The present and future of the commercial application of FT-boar semen should be not negatively influenced by the excellent fertility levels achieved with fresh or cooled semen. Irrespective of current limitations, FT-spermatozoa plays an important role in certain sectors of the pig industry, where good fertility results can already be achieved, even under farm conditions. Despite these promising signs, there is considerable scope to achieve a wider utilisation of FTboar spermatozoa in commercial pig breeding.

Priorities for research need to be directed towards:

1. The standardisation of an optimal cryopreservation procedure. In spite of recent methodological improvements, further advances are necessary in order to both improve post-thaw sperm survival and prolong the functional life span of FT-spermatozoa. Research tools such as cryomicroscopy (see recent review of Holt et al., 2005) and the incorporation of new freezing devices such as "multi-thermal gradient" freezing (Arav et al., 2002) can help to achieve this goal. In addition, the development of genetic probes to identify "good" and "bad" freezer boars is expected. 
2. Freezing extenders need improvement. Current freezing extenders are basically the same as those used 30 years ago. The development of more effective extenders to both stabilise the sperm membranes and extend the functional life span of thawed spermatozoa is a major goal. Boar spermatozoa undergo lipid peroxidation during the freezing and thawing cycle. Addition of antioxidants or chelating agents such as vitamin E (Peña et al., 2003), glutathione (Gadea et al., 2004), butylated hydroxytoluene (Roca et al., 2004) or catalase and superoxide dismutase (Roca et al., 2005) in the freezing extender have proven effective.

3. Efforts should be geared towards the identification of subpopulations of FT-spermatozoa that maintain an intact fertilising capability. The overall percentage (usually $50 \%$ ) of surviving spermatozoa, normally assessed according to objective motility or/and intact plasma and acrosomal membranes, are the criteria currently used to define cryosurvival success. However, a definition of "good" freezer is not always a warranty for fertilising ability, particularly when doses with a low number of FT-spermatozoa are used (Rath, 2002). Not all boars considered "good" freezers achieve high rates of in vitro fertility (Gil et al., 2005), pointing out the limitations of current sperm evaluation tests to identify potentially fertile spermatozoa post-thaw. Based on the number of spermatozoa attached to the zone pellucida of oocytes after Al (Waberski et al., 1994), it seems that the fully functional sperm population in thawed samples is not higher than $10 \%$.

4. Development of techniques for accurate prediction (or at least estimation) of the time of ovulation is a priority. The fertility success for FT-semen in Al programmes is highly dependent of the interval between $\mathrm{Al}$ and ovulation. A sensor system using basic principles of immunological detection is currently under development for the automatic analysis of steroid hormone profiles in samples of saliva in sows (TT Mottram, Silsoe Research Institute, England, personal communication). For instance, a fall in oestradiol-17ß concentrations could be used as an estimator of ovulation time.

5. Sperm transport through the sow genital tract should be also improved, especially when FTspermatozoa are cervically deposited. Proper uterine myometrial contractility plays a major role during sperm transport. Although strategies to ensure this can be as simple as the use of the "boar effect" during Al; the exogenous application of compounds (including hormones such as oxytocin and prostaglandins) to stimulate myometrial contractions is also discussed (Langendijk et al., 2005). To the best of our knowledge, there are no results yet available of the effectiveness of the above mentioned approaches to improve fertility levels when using FT-semen for Al.

6. New insemination procedures that allow the deposition of semen intra-uterus offer interesting possibilities for a more effective use of FT-semen in commercial breeding. At present, DUI with as few as $1 \times 10^{9}$ total spermatozoa per dose yields acceptable fertility. Evaluation of the minimum sperm number per dose, of best insemination-timing and the number of inseminations per cycle are still needed to standardise DUI insemination strategies.

\section{Acknowledgements}

The authors would like to thank G. Carvajal, T. Cremades and M.A. Gil for their collaboration in work reported in this manuscript. The research of the authors has been supported by CICYT (AGF98-0533 and AGL01-0471) and INIA (RZ01-019), Madrid, Spain; FORMAS and SLF, 
Stockholm, Sweden. The SENECA Foundation, Murcia, Spain is acknowledged for funding a guest Professorship for Dr. H. Rodríguez-Martínez.

\section{References}

Arav A, Yavin S, Zeron Y, Natan D, Dekel I and Gacitua $H$ (2002) New trends in gamete's cryopreservation Molecular and Cellular Endocrinology 187 77-81

Bathgate R, Eriksson B, Maxwell WMC and Evans G (2005) Low dose deep intrauterine insemination of sows with fresh and frozen-thawed spermatozoa Theriogenology 63 553-554

Bolarín A, Roca J, Rodríguez-Martínez $\mathrm{H}$, Hernández M, Vazquez JM and Martínez EA (2005) Dissimilarities in sows' ovarian status at the insemination time could explain differences in fertility between farms when frozen-thawed semen is used Theriogenology (in press)

Bussiere JF, Bertaud G and Guillouet P (2000) Conservation de la semence congelée de verrat. Resultats in vitro et après insemination [Conservation of boar semen by freezing. Evaluation in vitro and after inseminationl Journees de la Recherche Porcine en France 32 429-432

Bwanga CO (1991) Cryopreservation of boar semen. 1: A literature review Acta Veterinary Scandanavia 32 $431-53$

Carvajal C, Cuello C, Ruiz M, Vázquez JM, Martínez EA and Roca I (2004) Effects of centrifugation before freezing on boar sperm cryosurvival fournal of Andrology 25 389-396

Crabo BG and Einarsson S (1971) Fertility of deep frozen boar spermatozoa Acta Veterinary Scandanavia 12 125-127

Devireddy RV, Fahrig B, Godke RA and Leibo SP (2004) Subzero water transport characteristics of boar spermatozoa confirm observed optimal cooling rates Molecular Reproduction and Development 67 44657

Eriksson BM, Petersson $\mathbf{H}$ and Rodriguez-Martinez $\mathbf{H}$ (2002) Field fertility with exported boar semen frozen in the new FlatPack container Theriogenology 58 1065-1079

Eriksson BM and Rodriguez-Martinez $\mathbf{H}$ (2000) Effect of freezing and thawing rates on the post-thaw viability of boar spermatozoa frozen in FlatPacks and Maxi-straws Animal Reproduction Science 63 205220

Eriksson BM, Vazquez IM, Martinez EA, Roca J, Lucas X and Rodriguez-Martinez H (2001) Effects of holding time during cooling and of type of package on plasma membrane integrity, motility and in vitro oocyte penetration ability of frozen-thawed boar spermatozoa Theriogenology 55 1593-1605

Fiser PS and Fairfull RW (1990) Combined effect of glycerol concentration and cooling velocity on motility and acrosomal integrity of boar spermatozoa frozen in $0.5 \mathrm{ml}$ straws Molecular Reproduction and Development 25 123-129
Fiser PS, Fairfull RW, Hansen C, Panich PL, Shrestha IN and Underhill L (1993) The effect of warming velocity on motility and acrosomal integrity of boar sperm as influenced by the rate of freezing and glycerol level Molecular Reproduction and Development 34 190-195

Flowers WL (2001) Increasing fertilization rate of boars: Influence of number and quality of spermatozoa inseminated fournal of Animal Science $\mathbf{8 0}$ (Supplement 1) E47-E53

Gadea I, Selles E, Marco MA, Coy P, Matas C, Romar R and Ruiz $S$ (2004) Decrease in glutathione content in boar sperm after cryopreservation. Effect of the addition of reduced glutathione to the freezing and thawing extenders Theriogenology 62 690-701

Gerrits R], Lunney JK, Johnson LA, Pursel VG, Kraeling RR, Rohrer GA and Dobrinsky JR (2005) Perspeclives for artificial insemination and genomics to improve global swine populations Theriogenology 63 283-99

Gil, MA, Roca J, Cremades T, Hernandez $M$, Vazquez JM, Rodriguez-Martinez $H$ and Martinez EA (2005) Does multivariate analysis of post-thaw sperm characteristics accurately estimate in vitro fertility of boar individual ejaculates? Theriogenology 64 305-316

Graham EF, Rajamannan AHJ, SchmehI MKL, Maki-Laurila $M$ and Bower RE (1971) Preliminary report on procedure and rationale for freezing boar spermatozoa Al Digest 19 12-14

Hofmo PO and Grevle IS (2000) Development and commercial use of frozen boar semen in Norway. In Boar Semen Preservation IV pp 71-86 Eds LA Johnson and HD Guthrie. Allen Press, Lawrence, KS

Holt WV (2000a) Fundamental aspects of sperm cryobiology: the importance of species and individual differences Theriogenology 53 47-58

Holt WV $(2000 \mathrm{~b})$ Basic aspects of frozen storage of semen Animal Reproduction Science 623.22

Holt WV, Medrano A, Thurston LM and Watson PF (2005) The significance of cooling rates and animal variability for boar sperm cryopreservation: insights from the cryomicroscope Theriogenology 63370 382

Johnson LA (1985) Fertility results using frozen boar spermatozoa. In Deep freezing of boar semen pp 199 224 Eds L.A Johnson and $K$ Larsson. Published by Swedish University of Agricultural Sciences and United States Department of Agriculture.

Johnson LA, Weitze KF, Fiser P and Maxwell WM (2000) Storage of boar semen Animal Reproduction Science $62 \quad 143-172$

King ME, McKelvey WA, Dingwall WS, Matthews KP, Gebbie FE, Mylne M), Stewart E and Robinson II 
(2004) Lambing rates and litter sizes following intrauterine or cervical insemination of frozen/thawed semen with or without oxytocin administration. Theriogenology 62 1236-1244

Kumar S, Millar JD and Watson PF (2003) The effect of cooling rate on the survival of cryopreserved bull, ram, and boar spermatozoa: a comparison of two controlled-rate cooling machines Cryobiology 46 246253

Langendijk P, Soede NM and Kemp B (2005) Uterine activity, sperm transport, and the role of boar stimuli around insemination in sows Theriogenology 63500 513

Martinez EA, Vazquez IM, Roca I, Lucas X, Gil MA, Parrilla I, Vazquez JL and Day BN (2002) Minimum number of spermatozoa required for normal fertility after deep intrauterine insemination in non-sedated sows Reproduction 123 163-170

Martinez EA, Vazquez, JM, Roca J, Lucas X, GiI MA and Vazquez JL (2001) Deep intrauterine insemination and embryo transfer in pigs Reproduction Supplement $58301-311$

Mburu IN, Einarsson S, Dalin AM and RodriguezMartinez H (1995) Ovulation as determined by transrectal ultrasonography in multiparous sows: relationships with oestrous symptoms and hormonal profiles Zentralblatt fur Veterinarmedizin. Reihe $\mathbf{A} \mathbf{4 2}$ 285-292

Medrano A, Anderson J, Millar JD, Holt WV and Watson PF (2002) A custom-built controlled-rate freezer for small sample cryopreservation studies Cryobiology Letters 23 397-404

Peña FJ, Dominguez JC, Carbajo M, Anel L and Alegre B (1998) Treatment of swine summer infertility syndrome by means of oxytocin under field conditions Theriogenology 49 829-836

Peña FJ, Johannisson A, Wallgren $M$ and Rodriguez Martinez H (2003) Antioxidant supplementation in vitro improves boar sperm motility and mitochondrial membrane potential after cryopreservation of different fractions of the ejaculate Animal Reproduction Science 78 85-98

Pursel VG and Johnson LA (1971) Procedure for the preservation of boar spermatozoa by freezing United States Department of Agriculture, Agricultural Research Service Bulletin 44-227 1-5

Rath D (2002) Low dose insemination in the sow-a review Reproduction in Domestic Animals 37 201205

Reed HCB (1985) Current use of frozen boar semen Future need of frozen boar semen. In Deep freezing of boar semen pp 225-238 Eds LA Johnson and K Larsson. Published by Swedish University of Agricultural Sciences and United States Department of Agriculture.

Roca J, Carvajal G, Lucas X, Vázquez JM and Martínez EA (2003) Fertility of weaned sows after deep intrauterine insemination with a reduced number of frozen-thawed spermatozoa Theriogenology 60 77-87

Roca J, Gil MA, Hernandez M, Parrilla I, Vazquez JM and Martinez EA (2004) Survival and fertility of boar spermatozoa after freeze-thawing in extender supplemented with butylated hydroxytoluene fournal of Andrology 25 397-405

Roca J, Lucas X, Gil MA, Vázquez JM, Carvajal $G$ and Martínez EA (2000) Motility and in vitro penetrating ability of cooled and frozen-thawed spermatozoa from identical boars In Boar Semen Preservation IV pp 71-86 Eds LA Johnson and HD Guthrie. Allen Press, Lawrence, KS

Roca J, Carvajal G, Centurión F, Lucas X, Vázquez JM and Martinez EA (2002) Fertility of cryopreserved boar spermatozoa after deep intrauterine insemination: effect of time of insemination relative to ovulation Reproduction in Domestic Animals 37249

Roca J, Rodriguez MJ, Gil MA, Carvajal G, Garcia EM, Cuello C, Vazquez JM and Martinez EA (2005) Survival and in vitro fertility of boar spermatozoa frozen in the presence of superoxide dismutase and/or catalase Journal of Andrology 26 15-24

Rodriguez-Martinez H, Saravia F, Wallgren M, Tienthai P, Johannisson A, Vázquez IM, Martínez E, Roca J, Sanz L and Calvete IJ (2005) Boar spermatozoa in the oviduct Theriogenology $63514-535$

Salamon S and Maxwell WMC (1995) Frozen storage of ram semen II. Causes of low fertility after cervical insemination and methods of improvement Animal Reproduction Science 38 1-15

Saravia F, Wallgren $M$, Nagy S, Johannisson $A$ and Rodriguez-Martinez H (2005) Deep freezing of concentrated boar semen for intra-uterine insemination: effect on sperm viability Theriogenology 63 13201333

Soede N, Hazeleger W and Kemp B (1998) Follicle size and the process of ovulation in sows as studied with ultrasound Reproduction in Domestic Animals 33239. 244

Soede NM and Kemp B (1997) Expression of oestrus and timing of ovulation in pigs fournal of Reproduction and Fertility Supplement 52 91-103

Sommer JR, Collins EB, Neiding T, Rozeboom K, Wong $F$ and Petters RM (2002) Conservation and regeneration of transgenic lines of swine by semen cryopreservation and artificial insemination Laboratory Animal (NY) 31 25-31

Thurston LM, Watson PF, Mileham AJ and Holt WV (2001) Morphologically distinct sperm subpopulations defined by Fourier shape descriptors in fresh ejaculates correlate with variation in boar semen quality following cryopreservation Journal of Andrology 22 382-394

Thurston LM, Siggins K, Mileham Al, Watson PF and Holt WV (2002) Identification of amplified restriction fragment length polymorphism markers linked to genes controlling boar sperm viability following cryopreservation Biology of Reproduction 66545 . 554

Thurston LM, Holt WV and Watson PF (2003) Post-thaw functional status of boar spermatozoa cryopreserved using three controlled rate freezers: a comparison Theriogenology 60 101-113

Vishwanath $\mathbf{R}$ and Shannon P (2000) Storage of bovine 
semen in liquid and frozen state Animal Reproduction Science 62 23-53

Waberski D, Weitze KF, Gleumes T, Schwarz M, Willmen $Y$ and Petzoldt R (1994) Effect of time of insemination relative to ovulation on fertility with liquid and frozen boar semen Theriogenology $42831-840$

Wagner HG and Thibier M (2000) World statistics for artificial insemination in small ruminant and swine Proceedings of the $14^{\text {th }}$ International Congress on Animal Reproduction, Stockholm, Sweden. Abstracts vol. 2,153

Watson PF (1995) Recent developments and concepts in the cryopreservation of spermatozoa and the assessment of their post-thawing function Reproduction Fertility and Development 7 871-891

Watson PF (2000) The causes of reduced fertility with cryopreserved semen. Animal Reproduction Science 60-61 481-492

Watson PF and Behan IR (2002) Intrauterine insemination of sows with reduced sperm numbers: results of a commercially based field trial Theriogenology 57 1683-1693

Weitze KF (2000) Update on the worldwide application of swine Al. In Boar semen preservation IV pp 141146 Eds L.A Johnson and HD Guthrie. Alten Press, Lawrence, KS

Weitze KF, Rath D and Baron G (1987) Neue Aspekte der Tiefgefrierkonservierung von Ebersperma in Plastikröhren [New aspects of preservation of boar sperm by deep freezing in plastic tubes] Deutsche Tierärztliche Wochenschrift 82 261-267

Woelders H (1997) Fundamentals and recent development in cryopreservation of bull and boar semen Veterinary Quarterly 19 135-138

Wongtawan T, Saravia F, Wallgren $M$, Caballero I and Rodríguez-Martinez H (2005) Fertility after deep intra-uterine artificial insemination of concentrated lowvolume boar semen doses Theriogenology (In press) 